\title{
Hypothalamic Mass Detected in Langerhans Cell Histiocytosis
}

\author{
Ryosuke Takase ${ }^{1}$, Yasuhiro Nakano ${ }^{1}$, Shin Morizane $^{2}$ and Fumio Otsuka ${ }^{1}$ \\ Key words: diabetes insipidus, FDG-PET, Langerhans cell histiocytosis (LCH), hypopituitarism and skin \\ biopsy
}

(Intern Med 60: 1795, 2021)

(DOI: 10.2169/internalmedicine.5946-20)
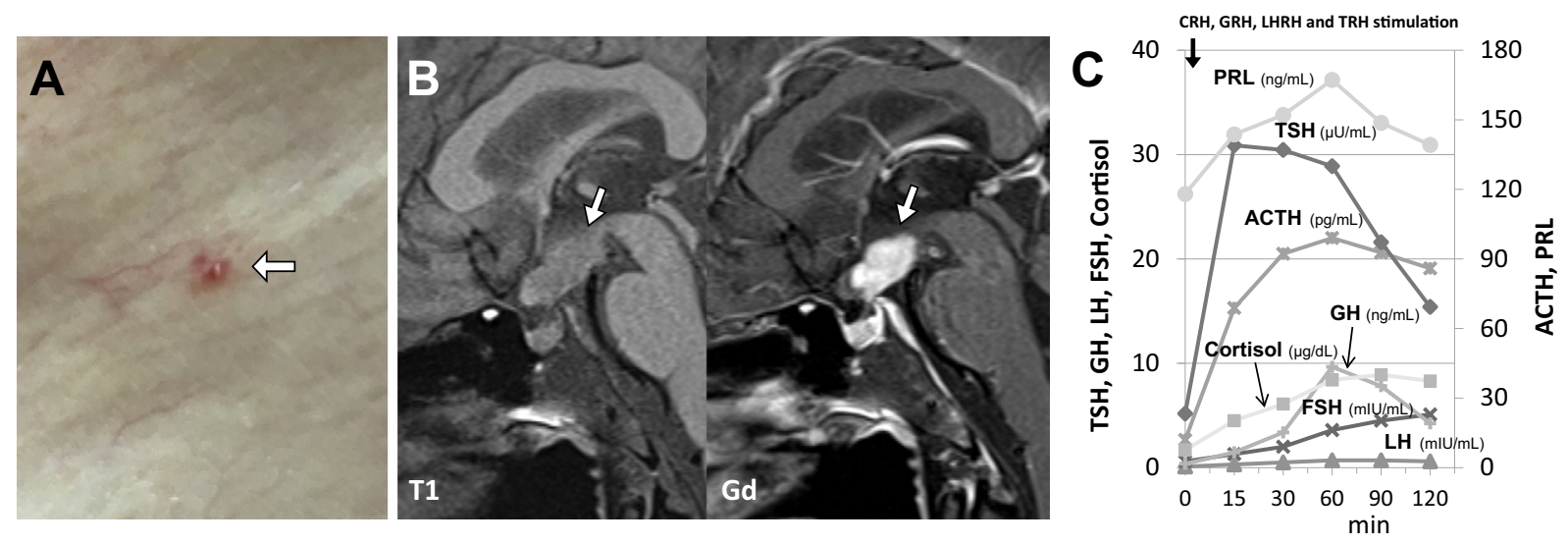

Picture.

A 61-year-old woman suffering from papules (Picture A) was diagnosed with Langerhans cell histiocytosis ( $\mathrm{LCH}$ ) by a skin biopsy. Although the patient was asymptomatic, aside from rashes, fluorodeoxyglucose positron emission tomography (FDG-PET) showed a high uptake in the occipital bone, and endocrine workup demonstrated pituitary dysfunction. Magnetic resonance imaging revealed a tumorous lesion in the basal hypothalamus with gadolinium enhancement and disappearance of the posterior pituitary bright spot (Picture B). Pituitary stimulation tests revealed hypothalamic damage (Picture C). Polyuria and hypernatremia developed after the patient began taking hydrocortisone and levothyroxine, which were improved by desmopressin administration. Hypothalamic damages occur in $10 \%$ of central nervous system lesions of LCH (1). The presence of a hypothalamic mass is diagnostic for $\mathrm{LCH}$ in patients who had previously been diagnosed with multifocal LCH (2). Central diabetes insipidus with hypopituitarism in $\mathrm{LCH}$ is refractory to chemoradiation but requires permanent hormone replacement. Careful screening of systemic lesions, including skin and endocrinological evaluations, are required for patients with asymptomatic LCH.

The authors state that they have no Conflict of Interest (COI).

\section{References}

1. Grois NG, Favara BE, Mostbeck GH, Prayer D. Central nervous system disease in Langerhans cell histiocytosis. Hematol Oncol Clin North Am 12: 287-305, 1998.

2. Radojkovic D, Pesic M, Dimic D, et al. Localised Langerhans cell histiocytosis of the hypothalamic-pituitary region: case report and literature review. Hormones 17: 119-125, 2018.

The Internal Medicine is an Open Access journal distributed under the Creative Commons Attribution-NonCommercial-NoDerivatives 4.0 International License. To view the details of this license, please visit (https://creativecommons.org/licenses/ by-nc-nd/4.0/).

\footnotetext{
${ }^{1}$ Department of General Medicine, Okayama University Graduate School of Medicine, Dentistry and Pharmaceutical Sciences, Japan and ${ }^{2}$ Department of Dermatology, Okayama University Graduate School of Medicine, Dentistry and Pharmaceutical Sciences, Japan Received: July 23, 2020; Accepted: October 13, 2020; Advance Publication by J-STAGE: December 29, 2020 Correspondence to Dr. Fumio Otsuka, fumiotsu@md.okayama-u.ac.jp
}

(C) 2021 The Japanese Society of Internal Medicine. Intern Med 60: 1795, 2021 